\title{
Multicriteria analysis and information modelling in management of built environment
}

\author{
Nikolai Bolshakov ${ }^{1 *}$, Vladimir Badenko ${ }^{1}$, Julia Volkova $^{1}$, Alberto Celani ${ }^{2}$, and Lei Zhang ${ }^{3}$ \\ ${ }^{1}$ Peter the Great St. Petersburg Polytechnic University, Polytechnicheskaya, 29, St.Petersburg, \\ 195251, Russia \\ 2 Politecnico di Milano, Piazza Leonardo da Vinci, 32, Milano, 20133, Italy \\ ${ }^{3}$ East China Normal University, Dongchuan Rd., 500, Shanghai, 200241, China
}

\begin{abstract}
Building Information Modelling (BIM) proves to be the most urgent trend in construction for the last years. Still the major part of this issue is dedicated only to the first stages of building lifecycle: design and construction. This article goal is to provide a critical overview on recent achievements in BIM application for the different steps of building lifecycle as well as ongoing digitalization of facility management. The paper explores the importance of applying mathematical modelling and multicriteria analysis such as Analytical Hierarchy Process (AHP) and fuzzy logic in management of built environment and provides recent examples of such applications consequently exploring its potential. Method of analysis in this article is horizontal analysis of publication activity in related research topic. Different levels of digital built environment are considered: from building (BIM) to the whole city (GIS). The result of the research reveal that emergence of scan-to-BIM technology brings benefits not only for the buildings which are designed with BIM models (current situation in the market) but for the buildings which are already built (asbuilt BIM).
\end{abstract}

\section{Introduction}

Building Information Modelling is a phenomena that has been quickly reshaping the construction sector for the last years [1]. The number of SCOPUS indexed articles mentioning "bim" and "building information modelling" is reaching a thousand a year but still most of these articles are dedicated to the design or construction phase of the project. Construction industry is considered slow to adopt changes [2] due to its complexity so taking into account the fact that information modelling is quiet modern direction in the built environment studies it is clear that adaptations slowly start form the basic construction stages. Still there are significant achievements and potential in exploring information modelling from the management and maintenance point of view. Ilter et al. classify the direction of BIM development in terms of maintenance and refurbishment on the scale of one building in following subdirections: building survey and as-built BIM, modelling and managing energy, design assessment, access to and integration of maintenance information

\footnotetext{
*Corresponding author: nikolaybolshakov7@gmail.com
} 
and knowledge, and information exchange and interoperability [3]. Multicriteria analysis techniques such as analytical hierarchy process theory and fuzzy logic are used not only in GIS studies but also on a building level. Still Antucheviciene et al. point out that civil engineering issues under uncertainty are rarely discussed [4]. The researchers highlight following areas of civil engineering: design of sustainable and energy efficient buildings, building information modelling, and assurance of security and safety of built property.

This article is dedicated to covering the current state of information modelling in maintenance and management of built environment with particular focus on the way in which such methods as multicriteria analysis or fuzzy logic can be benchmarked from pure mathematical studies.

\section{Methods}

As the study is dedicated to the review of how information modelling is used in terms of management of built environment and how often AHP or fuzzy sets are used in this terms, the method is based on the analysis of existing literature as well as the achievements of public sector in the considered issue.

A significant literature review concerning the topic of BIM in existing building has been published five years ago [5] Unlike the research work of Volk et al. our study focuses on the ways in which mathematical analysis can be applied in terms of BIM for existing building.

The investigation process has been deconstructed in the following subcategories:

- multicriteria analysis and GIS (digital twins of cities) for site selection;

- BIM in management of built environment, digitalization of facility management;

- scan-to-BIM technology;

- BIM-GIS integration (digital twin hierarchy in concept of Smart City).

We consider it necessary to view lifecycle of a building on several levels of digital built environment: from BIM to GIS. An example of achieved results in exploring the GISrelated study (site-selection) as an input for the BIM lifecycle of the building is presented in the next chapter. The study has been carried out using ArcGIS and MathCAD software.

The review has been mostly held using the articles included in SCOPUS database. The current state of multicriteria analysis and information modelling in management of built environment has been assessed using such techniques as horizontal analysis of publication activity, which is normally used in financial studies.

\section{Results}

The results of the review are organized respectively to the subdivision mentioned above.

\subsection{Multicriteria Analysis and GIS for site selection}

The survey of the literature in SCOPUS database has shown the following results (fig.1). The graph above demonstrates that among those articles which discover the topics of site selection in geoinformation system environment the share of research which use multicriteria analysis is growing permanently and by the current year almost half of the GIS-site-selection papers inevitably discuss multicriteria decision making. The above mentioned share is growing not proportionally to the total number of articles which is assumed to represent the research interest.

There are numerous examples of the benefits from applying multicriteria analysis and fuzzy logic in site selection. The combination of these techniques provides an opportunity 
to explore more deeply the heterogeneous nature of qualitative and quantitative distribution of factors in the urban land [6].

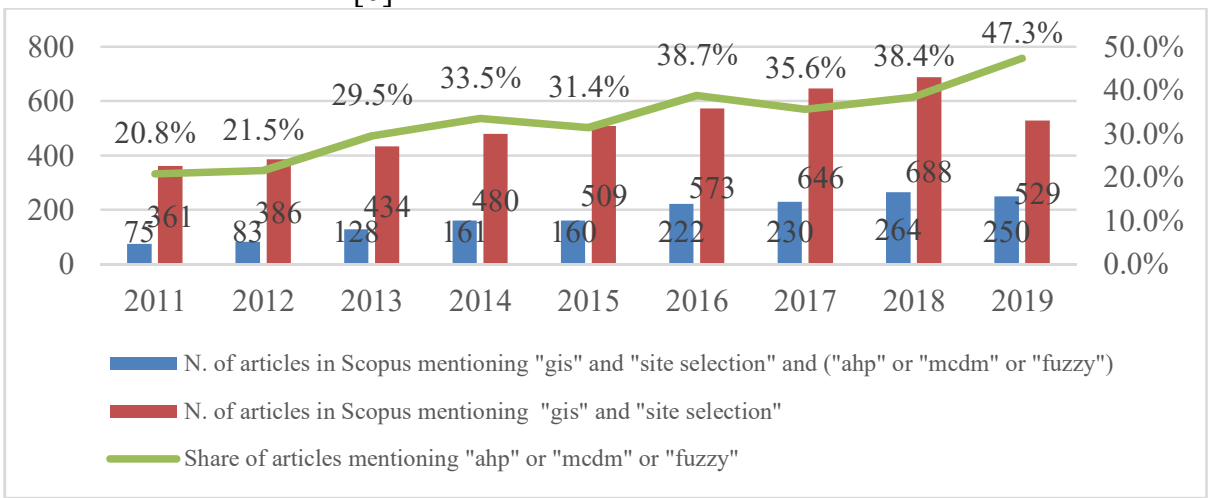

Fig. 1. Research activity in topics of multicriteria decision making among the articles mentioning GIS and site selection as of August, 2019

The significance of applying analytical hierarchy process theory in site selection process using the largest scale of built environment information modelling (GIS) has proved itself already [7]. The multicriteria nature of urban transformations may be assessed from several points of view: economic, ecological [8], social, technological, political, etc.

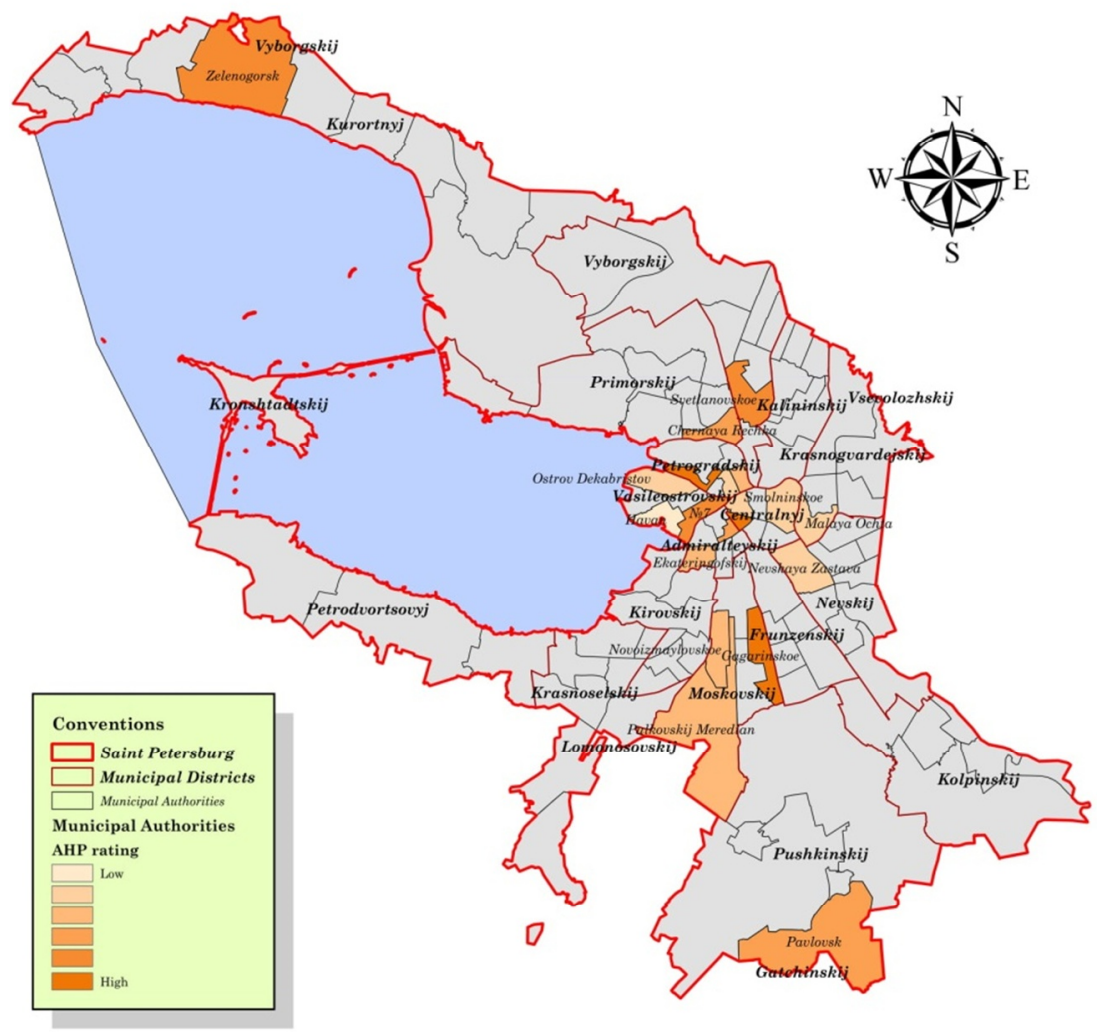

Fig. 2. Application of analytical hierarchy process method in the site-selection task in geoinformation system environment (Saint Petersburg case study) 
The figure above is a practical result of a site-selection case study in Saint-Petersburg carried out using ArcGIS and MathCAD software and based on a spatial data and multicriteria analysis (AHP). The basic steps of theoretical base of the developed method has been discussed earlier [7]. The result above represents the site suitability calculated according to the input requirements of the potential building. The AHP rating of the municipal authorities has been calculated according to the formula 1 below and later linked to the ArcGIS software through automatic connection by the name of a municipal authority.

$$
P_{A H P} \times W_{A H P}=R_{A H P}
$$

where $\mathrm{P}_{\mathrm{AHP}}$ are the performances of municipal authorities assessed as the eigenvectors of matrixes of AHP pairwise comparisons by several criteria, $\mathrm{W}_{\mathrm{AHP}}$ is the eigenvector of matrix of pairwise AHP comparisons of criteria weights, $\mathrm{R}_{\mathrm{AHP}}$ is the rating of municipal authorities.

The parameters used in the multicriteria analysis in GIS shall become the information used in the management of digital twin as it affects the properties of the built environment component.

\subsection{BIM and management of built environment. Digitalization of the facility management.}

Building information modelling starts to be integrated not only in construction and design but also in maintenance and management [9].

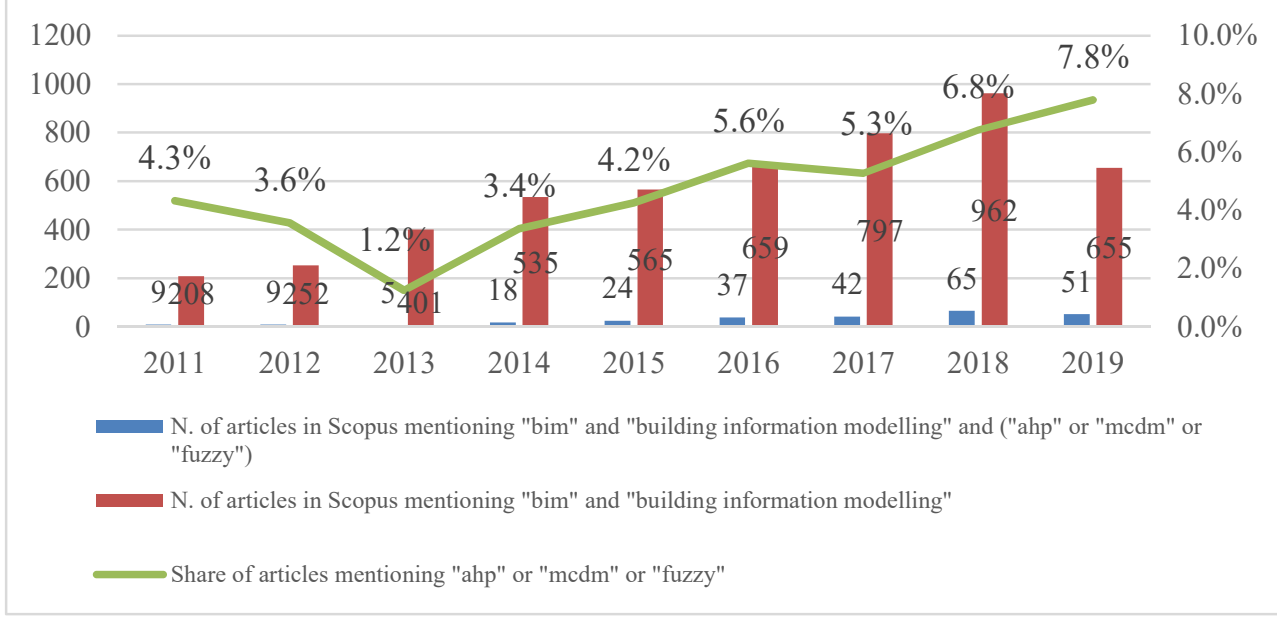

Fig. 3. Research activity in topics of multicriteria decision making among the articles mentioning BIM as of August, 2019

The search of BIM-related articles have been carried out as follows: among the articles mentioning words building, information and modelling have been selected the ones which mention exactly the word "BIM".

Still the potential of integrating multicriteria decision making techniques such as AHP or fuzzy logic is not quietly developed. The graph above represents the small number of SCOPUS articles mentioning "AHP" or "MCDM" (multicriteria decision making) or "fuzzy" among those mentioning "building information modelling" and "bim". Even though the percentage is low there is a clear trend if increasing interest in the MCDM in the BIM studies according to the proportional vertical analysis.

Considering the idea of the three levels of facility management as: strategic, tactical and operational it can be considered the digitalization in the three parts of the process.

The research must also include the relationship between the BIM and the management 
of the built environment, considering both an aspect of scale (of the building and urban) [10] or of impact on the design of services. It should not be forgotten that the management of the built environment, like the facility management, must not be limited to maintenance management alone. Facility management is the set of services for the person, the building and the business [11] The aspect of innovation is fundamental when the information is usable by those who must manage the real estate assets, without leading to a "data paradox", which is an excess of data but little possibility of obtaining information useful for the management of the building at operational level and asset management at strategic asset management level. [12] Another important aspect is that of interoperability and the possibility of using this approach for civil works that are not properly those easy to access for BIM and the technologies mentioned. [13] Those aspects represent the boarders of the traditional BIM applications and must be considered as the true vision for a development of a set of technologies that can serve any aspect of the built environment management: from building management to asset management, from civil engineering works to urban facility management.

The survey of the literature in SCOPUS database has shown the following results (see figure 4):

The research interest in the topics of building information modelling is growing for the last ten years not proportionally to the number of papers mentioning facility management. It means that each year more and more articles which discuss facility management inevitably mention building information modelling.

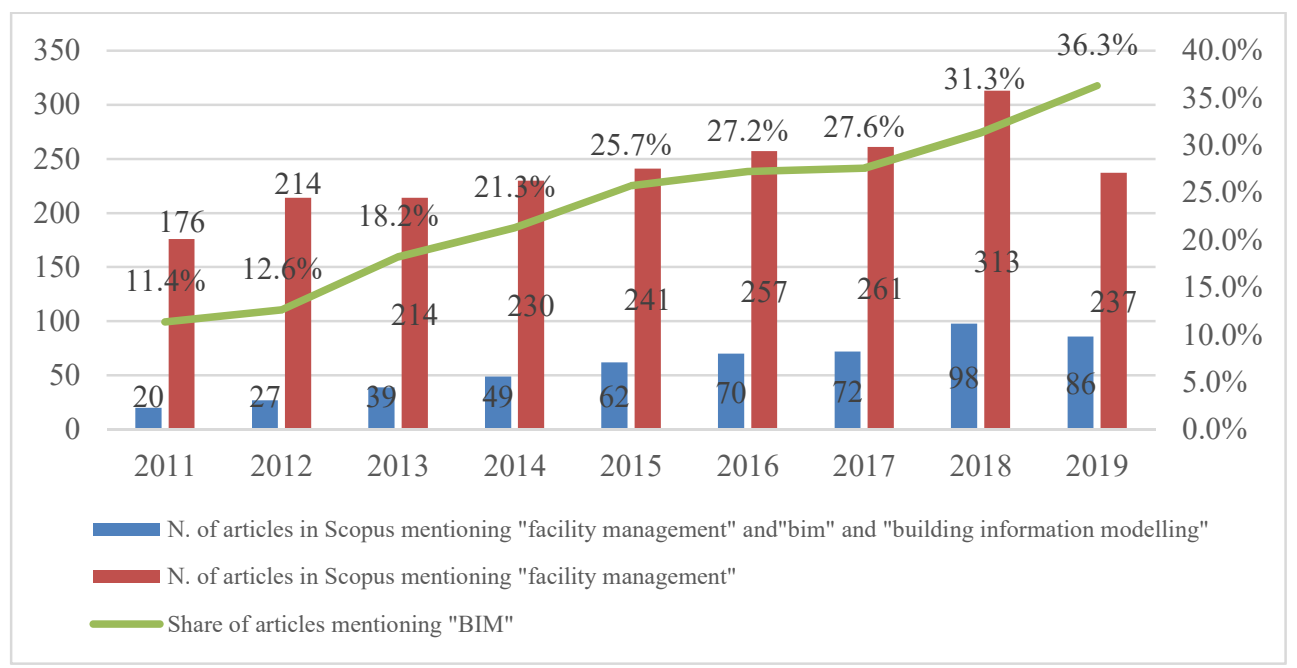

Fig. 4. Research activity in topics of building information modelling among articles mentioning facility management as of August, 2019

The search of BIM-related articles has been carried out as follows: among the articles mentioning words building, information and modelling have been selected the ones which mention exactly the word "BIM".

In order to identify the articles mentioning facility management the search has been focused on the exact combination of words "facility management" due to the fact that the initial search of the words "facility" and "management" separately has shown numerous articles from other scientific fields not related with construction. 


\subsection{Scan-to-BIM technology}

The scanning of point clouds and creation of BIM models of existing buildings and buildings under construction can be considered as an input for digital asset management or digital facility management.

The number of papers mentioning scan-to-BIM keeps on growing for the last years:

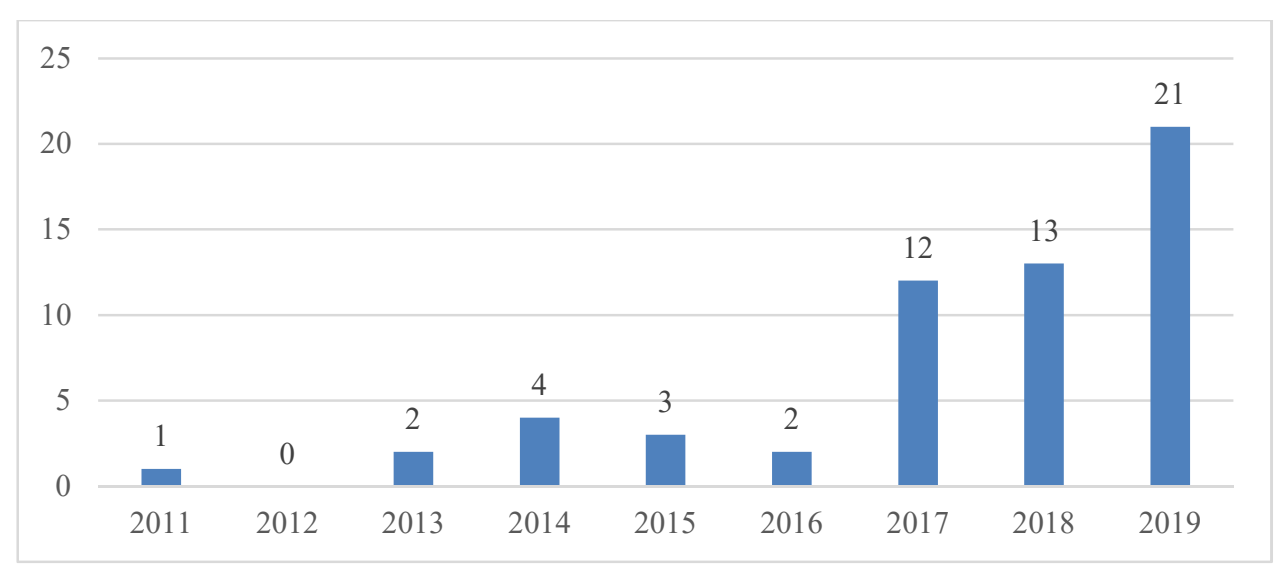

Fig. 5. Number of articles mentioning "scan-to-BIM" indexed in SCOPUS as of August, 2019.

Taking into account that by the August, 2019 the number of articles indexed in Scopus in current year is already 21, it is possible to assume that it will almost double by the end of the year.

Scan-to-BIM technology is one of the major innovations [14] in construction industry. Even though essentially scan-to-BIM technology is linked to historical buildings and scanning the existing buildings, there are some researches in the urban open space scanning [15]. The researches proves the assumption that open urban space scanning can provide significant savings in terms of both time and cost for public tender, maintenance and construction cost. The border between two layers of built environment is considered in this case: building and the whole city.

Another challenge which is now widely discussed is the transformation of the point clouds obtained through laser scanning into useful information, usable for the management process [16]. One of the current researches focuses on the case study comparing two possible methods: Advanced 3D modelling and using Revit BIM software [17], going to the conclusion that having both advantages and disadvantages, both methods shall better be used in a combination. Current achievements of transferring scanned point clouds into actual objects provide the methods such voxel grid [18] which automatically generates proposals for scanned objects: beam, column, roof, stairs, window frame, etc.

Time-consuming scan-to-BIM process needs to be optimized, so necessary add-inns for the most used BIM software such as Revit are currently developed [19].

\subsection{BIM-GIS integration}

As it is described in the first subchapter site selection process carried out with the help of geoinformation system environment can be considered as an input for BIM environment as the area and the site influence the properties of the building. It is an example of linkage between BIM and GIS environments: two different levels of built environment digitalization, building and city respectively. GIS data are the input for criteria in site selection which transforms into BIM data in the beginning of building lifecycle [20] linking 
for example environmental data on different layers. The linkages between the software commonly used in BIM and GIS, such as IFC and shapefiles respectively are currently improving [21].

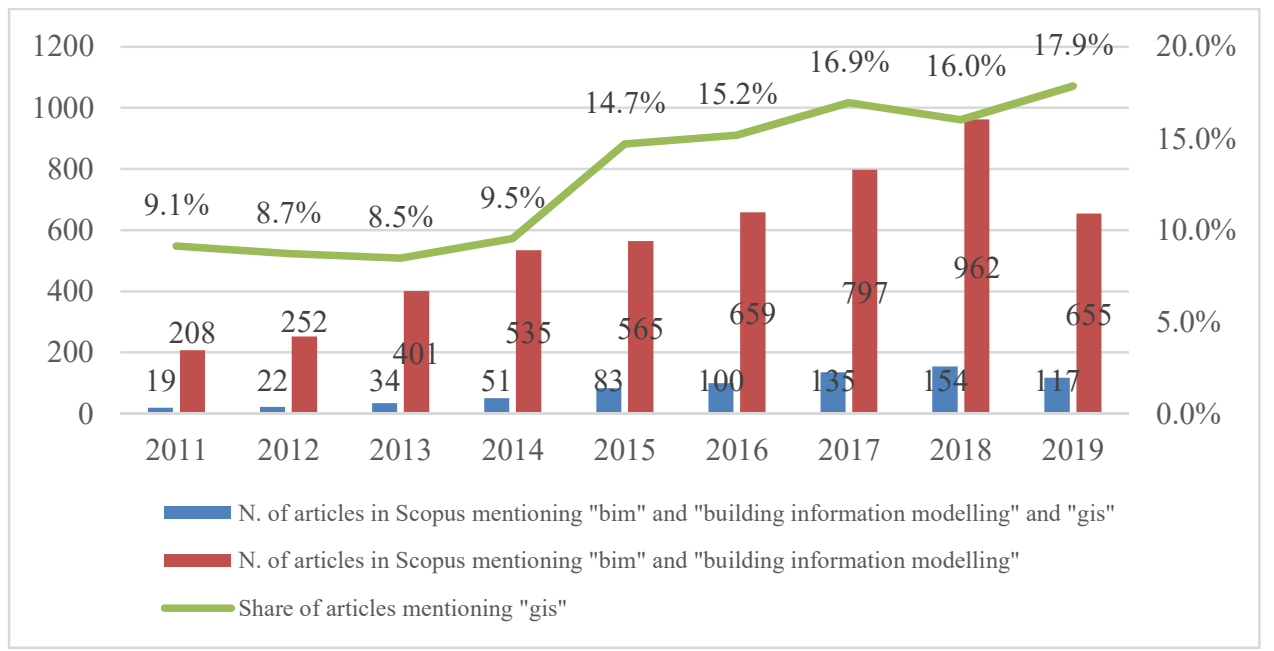

Fig. 6. Research activity in topic of GIS among the articles mentioning BIM as of August, 2019

The figure above summarizes the recent research interest on the intersection of BIM and GIS. The increasing share of articles mentioning both geoinformation systems and building information modelling illustrates the integration of built environment digitalization on various levels from city to a single building.

\section{Conclusions}

Modern digitalization of built environment is currently taking place among several layers starting with the elements of the building in building information modelling (BIM) environment and finishing with the whole city or regional territories in geoinformation system (GIS) environment while the research interest in the intersection of this two fields of study keeps on growing. Practical applications of digital built environment imply multicriteria decision making more each year. Still these methods or fuzzy logic are more frequently found in GIS studies rather than BIM. The BIM and GIS data are related as levels of digital built environment, output data from one of these layers might be an input for another. This novel approach is proven by the example of site selection method developed in GIS environment but providing a result for the beginning of a BIM-lifecycle of a building. Digitalization of facility management can make building maintenance cheaper and optimize real estate management which means that the emergence of scan-toBIM technology might bring benefits not only for the buildings which are designed with BIM models (current situation in the market) but for the buildings which are already built (as-built BIM).

The research is carried out with the financial support of the Ministry of Science and Higher Education of Russian Federation within the framework of the Federal Program "Research and Development in Priority Areas for the Development of the Russian Science and Technology Complex for 2014-2020". The unique identifier of the project is RFMEFI58417X0025. 


\section{References}

1. S. Azhar, M. Khalfan et al. Construction Economics and Building, 124, 15-28 (2012) DOI: 10.5130/AJCEB.v12i4.3032.

2. M D. Martinez-Aires, M. Lopez-Alonso et al. Safety science, 101, 11-18 (2018) DOI: 10.1016/j.ssci.2017.08.015

3. D. Ilter, E. Ergen. Structural Survey, 333, 228-256 (2015) DOI: 10.1108/SS-02-20150008

4. J. Antucheviciene, Z. Kala et al. Mathematical Problems in Engineering, 362579 (2015) DOI: 10.1155/2015/362579

5. R. Volk, J. Stengel et al. Automation in construction, 38, 109-127 (2014) DOI: 10.1016/j.autcon.2013.10.023

6. P.V. Gorsevski, K.R. Donevska et al. Waste management, 322, 287-296 (2012) DOI: 10.1016/j.wasman.2011.09.023

7. N. Bolshakov, V. Badenko et al. IOP Conference Series: Materials Science and Engineering, 365(2), 022052 (2018) DOI: 10.1088/1757-899X/365/2/022052

N.S. Bolshakov, V.L. Badenko et al. Magazine of Civil Engineering, 815, 15-24 (2018) DOI: 10.18720/MCE.81.2

8. V.V. Garmanov, V.L. Bogdanov et al. Vestnik Sankt-Peterburgskogo Universiteta, Seriya Geologiya i Geografiya, 4, 136-144 (2015)

9. D. Ilter, E. Ergen. Structural Survey, 333, 228-256 (2015) DOI: 10.1108/SS-02-20150008

10. K. Jieun, C. Hyunsang et al. Journal of the Korean Content Association, 14.4, 397-406 (2014)

11. G. Ciaramella, O. Tronconi. Asset management, IlSole 24, 280 (2012)

12. C.M. Eastman et al. BIM handbook: A guide to building information modeling for owners, managers, designers, engineers and contractors. (2011)

13. P. Jaehyun, L. Hyundong et al. Case study analysis on the application of BIM in Korea's civil engineering industry and securing of interoperability of BIM models, 5155 (2015) DOI: 10.14257/astl.2015.99.13

14. V.G. Borkovskaya. Applied Mechanics and Materials, 475. 1703-1706 (2014) DOI: 10.4028/www.scientific.net/AMM.475-476.1703

15. F. Guzzetti, K.I. Anyabolu et al. The International Archives of the Photogrammetry, Remote Sensing and Spatial Information Sciences, XLII-2/W11, 595-600 (2019) DOI: 10.5194/isprs-archives-XLII-2-W11-595-2019

16. F. Capocchiano, R. Ravanelli. International Archives of the Photogrammetry, Remote Sensing and Spatial Information Sciences, 422/W13, 769-776 (2019) DOI: 10.5194/isprs-archives-XLII-2-W13-769-2019

17. D. Visintini, E. Marcon et al. International Archives of the Photogrammetry, Remote Sensing and Spatial Information Sciences, 422/W11, 1137-1143 (2019) DOI: 10.5194/isprs-archives-XLII-2-W11-1137-2019

18. J. Chen, Y.K. Cho et al. Construction Research Congress 2018, 221-231 (2018) DOI: $10.1061 / 9780784481264.022$

19. F. Banfi. The International Archives of the Photogrammetry, Remote Sensing and Spatial Information Sciences, XLII-2/W11, 141-148 (2019) DOI: 10.5194/isprsarchives-XLII-2-W11-141-2019 
20. V.G. Borkovskaya. Applied mechanics and materials, 467, 287-290 (2014)

V. Borkovskaya, E. Degaev et al. MATEC Web of Conferences 193, 05027 (2018) DOI: 10.4028/www.scientific.net/AMM.467.287

21. J. Zhu, X. Wang et al. Automation in Construction, 102, 105-119 (2019) DOI: 10.1016/j.autcon.2019.02.014 